\title{
Guatemala's Catholic Revolution a history of religious and social reform, 1920-1968
}

\author{
Ana Lucía Álvarez Gutiérrez \\ Programa de doctorado en Historia \\ Universidad Iberoamericana \\ analucialvarez1@gmail.com
}

Bonar L. Hernández Sandoval, Guatemala 's Catholic Revolution a history of religious and social reform, 1920-1968, Notre Dame, Indiana, University of Notre Dame Press, 2019, 239 pp.

¿Cómo observar en la Iglesia católica una fuente de reformas durante la segunda mitad del siglo XX en Guatemala? ¿Cómo plantear el progresismo en dicho país sin ubicarlo únicamente como resultado del Concilio Vaticano II y la II Conferencia General del Episcopado Latinoamericano de Medellín en 1968? Estas son algunas preguntas que lanza Bonar L. Hernández Sandoval, doctor en Filosofía por The University of Texas at Austin quien ejerce actualmente como profesor de Historia en Iowa State University, en su más reciente publicación intitulada, Guatemala's Catholic Revolution a history of religious and social reform, 1920-1968. Una obra donde se propone una historia trasnacional en la que se entrelazan diversos actores y procesos a lo largo de diez lustros.

Este trabajo emprende un nuevo camino frente a los estudios que hasta el momento se han realizado. No se trata de un enfoque institucional en el que la Iglesia permanece estática (c) () No-Comercial 4.0 Internacional.

Secuencia. E-ISSN 2395-8464 http://secuencia.mora.edu.mx/

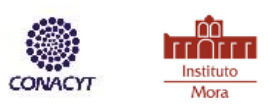


con una postura conservadora, como algunas veces se ha planteado; ni tampoco se centra únicamente en el catolicismo a nivel local permeado por la Guerra Fría y las trasformaciones posconciliares como los eventos que re-direccionaron el devenir de los creyentes y accionar progresista, como lo han mostrado los antropólogos en Guatemala. La investigación de Hernández da cuenta de una Iglesia dinámica, que sigue una línea de educación y formación religiosa marcada desde el Vaticano en un proceso de romanización, ${ }^{1}$ pero que al mismo tiempo lucha por adaptarse a las condiciones internacionales, nacionales y regionales, en contextos que van desde gobiernos liberales, hasta un mundo bipolar y dictaduras militares.

Es por ello que resulta tan importante la periodización propuesta por el autor, ya que el libro plantea la necesidad de entender el proceso de resurgimiento y adaptación de la iglesia católica en Guatemala tras los golpes sufridos bajo gobiernos liberales y la laxitud sacramental de los clérigos a principios del siglo XX, como un elemento fundamental para concebir los cambios progresistas, que tanto a nivel nacional como regional se dieron en la década de 1970 en dicho país. Así, a lo largo de 239 páginas organizadas en tres apartados, divididos cada uno de ellos en dos capítulos y acompañados de seis fotografías, a los que se les suma un epílogo, se va tejiendo, por medio de una amena narración, una compleja red en la que se entremezclan mayas, ladinos, clérigos, miembros de la misión Maryknoll, arzobispos, presidentes, dictadores y nuncios apostólicos.

Para ello, el autor deja ver un impresionante trabajo de archivo, en el que analiza documentos producidos por diversas instituciones. Revisa por un lado materiales ubicados en

\footnotetext{
'A decir de Rodolfo R. de Roux, la romanización se trata de un proyecto de "centralización y unificación institucional según las directivas de la Curia Romana, con miras a integrar a todos los católicos del mundo en torno a la figura del Papa en un momento en el que la Santa Sede se enfrentaba a los gobiernos liberales", Rodolfo R. de Roux, "La romanización de la Iglesia católica en América Latina: una estrategia de larga duración”, ProPosições, 2014, 33.
} 
Guatemala, tanto en el Archivo de la Provincia Franciscana, el Archivo Histórico de la Arquidiocesano de Guatemala, la Hemeroteca Nacional Clemente Marroquín Rojas y el Teologado Salesiano, esto le permite generar un diálogo entre las instituciones eclesiásticas guatemaltecas y el gobierno de dicho país, así como la postura que tomaron algunos sacerdotes diocesanos frente a las líneas de evangelización propuestas por el Vaticano.

Por otro lado, Hernández consulta el acervo de los misioneros Maryknoll, preservado en Ossing, Nueva York, en el Maryknoll Mission Archives, así como bibliografía y documentos ubicados en la biblioteca Benson Latin American Collection, de la Universidad de Texas en Austin, por medio de estas fuentes se puede apreciar el flujo de ideas entre los misioneros, sus impresiones sobre la región y el trabajo que realizaron, pero también los posicionamientos que el gobierno estadounidense asumió durante la Guerra Fría en relación con Latinoamérica. Por último, hace uso de un archivo poco consultado para los años en los que trascurre el estudio, se trata de los Archivos Secretos del Vaticano, en el que recoge diversas cartas, resúmenes y posturas que se asumen desde Roma en relación con la Iglesia y su labor política y social.

Basándose en estos documentos, Hernández es capaz de entretejer las relaciones entre el Vaticano y la Iglesia en Guatemala; la labor diplomática ejercida por los arzobispos frente al Estado, misma que a su vez posibilitó la construcción de un modus vivendi; así como el surgimiento de los laicos como nuevas figuras políticas a finales del siglo XX en dicho país centroamericano. En estas configuraciones el autor nos deja ver la importancia de la romanización, no solo como eje de reorganización del ejercicio sacerdotal, sino también como un proyecto de expansión de la fe que, en el caso del trabajo que misioneros del grupo 
Maryknoll ${ }^{2}$ realizaron en Guatemala, terminó trasformando la realidad socio-económica de los creyentes.

Para Hernández este es un episodio clave en el que se pueden leer los cambios que se generaron a nivel internacional, nacional y regional desde 1940, fecha en la que se asientan los primeros misioneros en las tierras altas, una zona de difícil acceso y cuya población era mayormente de indígenas mayas. Es por ello que el autor dedica tres capítulos para hablar del tema y pinta una cronología sistematizada en tres momentos distintos: un periodo de expansión, una época reformista y finalmente el nacimiento de una iglesia progresista. Todas estas etapas se delinean por diversas coyunturas y procesos políticos como la Guerra Fría, la Revolución de octubre en Guatemala y la época de dictaduras, sin mencionar el proyecto de “Alianza para el Progreso” emprendido por Estados Unidos para detener el avance del comunismo en Latinoamérica.

A decir del autor los misioneros arribaron a Guatemala en un contexto de reconciliación entre la institución católica y el Estado, tras un periodo de lucha durante gobiernos liberales, y una muestra clara de ello fue la llegada misma de los misioneros quienes antes de 1940, por su calidad de religiosos extranjeros probablemente no hubieran obtenido permiso de entrada. Esta aparente tolerancia religiosa no implicó que el trabajo de los misioneros estadounidenses hubiera sido fácil, ya que Hernández muestra, por medio del flujo epistolar que sostuvieron los hermanos Maryknoll, las tensiones que se desarrollaron entre los habitantes y los misioneros en sus primeros años de labor.

\footnotetext{
${ }^{2}$ Los hermanos Maryknoll son un grupo de misioneros provenientes de Estados Unidos que se dedicaron a evangelizar en diversas partes del mundo. Véase por ejemplo Juan F. Gorski et al., Missiological reflections on the Maryknoll centenary, Nueva York, Orbis, 2013.

Secuencia. E-ISSN 2395-8464
} 
Dichos religiosos describían a los mayas como paganos que adoraban dioses antiguos, visitaban chamanes, tomaban alcohol en exceso y tocaban la marimba dentro de la iglesia. Todas estas conductas, nos dice Hernández, fueron combatidas por los misioneros, para lo cual emprendieron, primero, un proyecto de enseñanza de los sacramentos en el que los indígenas jugaron un papel importante. Fueron los encargados de llevar la palabra de dios a sus lenguas natales y de esta forma evangelizar a sus coterráneos. Aunado a ello, comenzaron programas de alfabetización como medio de educación sacramental ante la falta de educación básica que existía en la zona.

Aunque este ejercicio logró formar a algunos catequistas indígenas, la época de mayor fuerza educativa parece ocurrir en la década de 1950, cuando los misioneros utilizaron otras tácticas de enseñanza, apoyados desde luego por los catequistas mayas, en los que la Acción Católica funcionó como elemento aglomerado de los grupos laicos, mientras intentaban dar una mayor participación a los seglares. Hernández describe con destreza las nuevas tecnologías utilizadas para la enseñanza de los sacramentos en una "doctrina tecnicolor" en la que se utilizaron láminas, tiras de película, tarjetas de doctrina, así como medios televisivos, además de la introducción de servicios de salud que restaran importancia a la labor curativa de los chamanes. Estas iniciativas iban menguando el terreno de los tradicionalistas y sumando adeptos para la corriente sacramental en las tierras altas.

Además, este emprendimiento educativo se desplegó en medio de un proceso de modernización emprendido por el gobierno guatemalteco, en un periodo conocido como revolucionario, en el que, tras un golpe orquestado por miembros del ejército, estudiantes y trabajadores en 1944, comenzaron una etapa de crecimiento integral, con planes de desarrollo democrático económico y educativo, en la que incluso se echa andar una reforma agraria. Todos estos cambios ejercidos desde el gobierno recibieron fuertes críticas por parte del Secuencia. E-ISSN 2395-8464 
arzobispo, quien las consideró como signos de comunismo, generando así tensiones ente el clero y el Estado, a tal punto que se habló de la posible expulsión de Rosell.

Frente a estas acciones, el gobierno aplaudió el trabajo de los Maryknoll e incluso solicitó la llegada de más misioneros. Esto nos muestra como el gobierno tenía una visión no monolítica de lo que era la Iglesia. Sin embargo, Hernández es muy cuidadoso al separar los motivos por los cuales los misioneros de las tierras altas realizaban su labor, para quienes la educación era un medio para enseñar la doctrina y expandir la idea de romanización, alejando así a los feligreses del comunismo; mientras que el Estado pretendía llevar el desarrollo a las zonas marginadas como un medio de modernización y formación de una sola nación.

Conforme avanzaban los años, sobre todo durante la década de 1960, los hermanos Maryknoll comenzaron a tomar cada vez tintes más sociales, periodo que Hernández denomina como progresista. El autor nos señala que los misioneros de las tierras altas estaban convencidos de que la única manera de detener el avance del comunismo era mejorar las condiciones de vida de los habitantes por lo que generaron comunidades autosuficientes de una revolución verde, todo esto bajo una dictadura que había derrocado a los gobiernos revolucionarios, con el avance de la Alianza para el Progreso emprendida por los estadounidenses, pero también en momentos de trasformación religiosa, en la década del Vaticano II, y la Conferencia de Medellín en 1968, que dieron elementos a los misioneros para cimentar desde la fe la necesidad de una mejora de las condiciones socioeconómica de los habitantes, hecho que venían trabajando desde una década antes.

Es así como Hernández consolida su tesis sobre la importancia de contextos más amplios y trasnacionales para entender el progresismo católico en Guatemala, alejándose de explicaciones simplistas, en relación con la importancia del Vaticano II logra matizar a una iglesia heterogénea, en donde el Vaticano también juega un papel importante y les devuelve a Secuencia. E-ISSN 2395-8464 
los misioneros su historicidad, considerando los motivos que llevaron a su accionar. Esto desde luego es un gran aporte a la historiografía, sobre todo al estudio de los grupos revolucionarios católicos de la segunda mitad del siglo XX en Latinoamérica. 